\title{
Head Impact Situations in Professional Football (Soccer)
}

\section{두)(i) $(9)$}

\author{
Authors \\ Florian Beaudouin, Daniel Demmerle, Christoph Fuhr, Tobias Tröß, Tim Meyer
}

\author{
Affiliations \\ Institute of Sports and Preventive Medicine, Saarland \\ University, Saarbrücken, Germany
}

Key words

health sequelae, concussion, traumatic brain injury, injury

patterns, epidemiology

received 15.09 .2020

revised 12.12 .2020

accepted 14.12 .2020

\section{Bibliography}

Sports Medicine International Open 2021; 5: E37-E44

DOI 10.1055/a-1338-1402

ISSN 2367-1890

(C) 2021. The Author(s).

This is an open access article published by Thieme under the terms of the Creative Commons Attribution-NonDerivative-NonCommercial-License, permitting copying and reproduction so long as the original work is given appropriate credit. Contents may not be used for commercial purposes, or adapted, remixed, transformed or built upon. (https://creativecommons. org/licenses/by-nc-nd/4.0/)

Georg Thieme Verlag KG, Rüdigerstraße 14,

70469 Stuttgart, Germany

\section{Correspondence}

Florian Beaudouin

Institute of Sports and Preventive Medicine, Saarland

University

Campus, Building B 8-2

66123 Saarbrücken

Germany

Tel.: + 49 681-302 70400, Fax. + 49 681-302 4296

florian.beaudouin@uni-saarland.de

\begin{abstract}
To assess head impact incidents (HIls) and to distinguish diagnosed head injuries from other incidents, a video observation analysis of match HIls was conducted in the German Bundesliga (2017/18 season). Video recordings of each match were screened to identify the respective events. Head injury data were identified by a prospective injury registry. $\mathrm{HII}$ and head injury incidence rates (IR) were calculated with $95 \% \mathrm{Cls}$. The total number of HIls was 1362 corresponding to an IR of 134.9/1000 match hours (95\% Cl 127.9-142.2). In 123 HII (IR $12.2,95 \% \mathrm{Cl} 10.2-14.5)$ the contact was classified as severe. Head contact with the opponent was the most frequent cause (85\%). The most frequent mechanism was in $44 \%$ (combined) the arm and elbow-to-head, followed by head-to-head and hand-to-head contacts (each $13 \%$ ). In $58 \%$, the Hlls occurred during header duels. Twenty-nine head injuries were recorded (IR 2.9, 95\% CI 2.0-4.1). Concussions/traumatic brain injuries accounted for $48 \%$, head/facial fractures $24 \%$, head/facial contusions $21 \%$, and lacerations/abrasions $7 \%$. The number of HIls not classified as concussions/more severe trauma was high. Identification of HIls and head injury severity should be improved during on-field assessment as many head injuries might go unrecognised based on the large number of HIls.
\end{abstract}

\section{Introduction}

Traumatic brain injuries (TBI) and particularly concussions in football have been the subject of increasing public discussions [1,2]. The predominant focus of research has been on head injuries and headers. The incidence of head injuries has recently been examined and shown to be lower in football compared to other collision sports [3-5].

However, the number of unreported head injuries is unknown. It can be assumed that head injuries, especially concussions, are more frequent than reported [4, 6-10]. Undiagnosed concussions may be the result of being overlooked by non-medical professionals and/or medical staff due to mild symptoms and signs or even because of trivialized post-injury symptoms by the players themselves [8,11-13]. As research has focused mainly on head injuries and headers being potential causes of brain damage and/or neurodegeneration in a cumulative manner, this narrowed perspective 
potentially disregards head impacts that fall below the injury threshold and are not classified as headers. These head impact incidents (HIls) may also play a role in terms of long-term sequelae. Previous research that used video observation detected incidence rates of approximately 33 and $53 \%$, respectively $[14,15]$. Concerning was that most of the players did not receive an assessment for concussion, although showing signs of a head injury. This underpins the importance of this third category that needs more attention besides severe head injuries and headers.

Consequently, the number of HIls with a biomechanical force transmitted to the head and brain or 'subconcussive blow', respectively, remains unclear. The severity of such HIls cannot be estimated easily. It appears significant to shed light on the grey area between heading the ball and diagnosed concussions. Furthermore, head injuries have been trivialised in the past and field assessment by non-medical and medical professionals remains challenging.

The question remains, how frequently do head impact incidents occur in professional football and how many of these are identified as head injuries? Therefore, this study aims to assess the incidence of a third category of HIls besides concussions (and more severe TBIs) and headers, by reviewing video material of all regular league matches of the $2017 / 18$ season in German professional football.

\section{Materials and Methods}

\section{Study sample and design}

A retrospective video observation of matches from the first German league (Bundesliga) was conducted to determine the number of HIls on players' heads across the $2017 / 18$ season (306 matches). The video recordings were obtained from the Deutsche Fußball Liga (DFL; German Football League organisation). To estimate the number of concussions and more severe incidents, a standardized pro- spective analysis of match head injuries was conducted with a media-based approach as previously published [3,4]. No approval from an ethics committee was required for this study [16] as all data were collected from public sources $[3,4]$.

\section{Head impact incident assessment}

An HII was defined as any external contact with a player's head (except regular heading) and consequently a visible biomechanical force transmitted to the brain. Each match of this season was screened to identify head injury-prone situations and the number of HIls. The process of incident assessment is shown in > Fig. 1. Two observers screened all matches during the $2017 / 18$ season. The first game day weekend ( 9 matches, 18 teams) was observed together to become familiar with the demands of the investigation and to harmonize assessments. All remaining game days of the first and second half of the season were assigned to one of the observers in a randomised manner. A priori, a detailed observation protocol was developed on the basis of two recently published studies $[4,17]$ and is displayed in > Table 1 . Severe contact was classified through subjective evaluation. This assessment was conducted by multiple inspections with different camera/angle perspectives. Both raters jointly checked these identified incidents in order to classify them as 'severe'. The incident was finally classified being severe when both raters agreed on the following: 1) high-speed collision; 2) obvious visible head acceleration after the contact; 3 ) players being unaware of the imminent contact; and 4) players didn't continue playing/running immediately.

\section{Head injury data collection}

Head injury data collection followed an a priori defined protocol and analysis plan [4]. A prospective injury registry by national publicly available data was used. Data were mainly identified by a structured search in the 'kicker Sportmagazin' magazine (online edi-
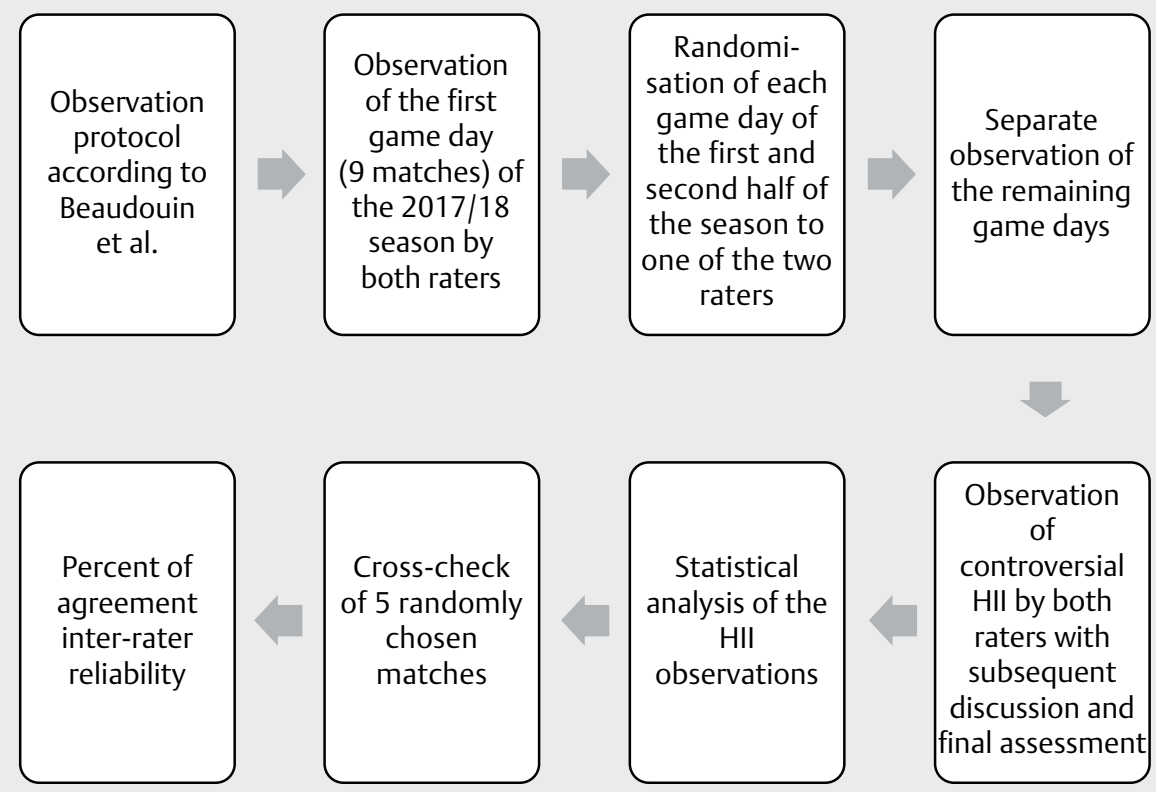

-Fig. 1 Process of head impact incident assessment. 
- Table 1 Observational items of head impact incidents.

\begin{tabular}{|c|c|}
\hline $\begin{array}{l}\text { Contact mechanisms between } \\
\text { opponent/team mate }\end{array}$ & $\begin{array}{l}\text { Hand-head, arm-head, elbow-head } \\
\text { Shoulder-head, trunk-head, pelvis/ } \\
\text { hip-head } \\
\text { Head-head } \\
\text { Upper leg-head, knee-head, lower } \\
\text { leg-head, foot-head } \\
\text { Trunk-trunk, shoulder-trunk }\end{array}$ \\
\hline Additional contact mechanisms & $\begin{array}{l}\text { Ball-head, ground-head, goalpost/ } \\
\text { object-head }\end{array}$ \\
\hline Player behaviour after HII & $\begin{array}{l}\text { Player touches head } \\
\text { Player falls to the ground } \\
\text { Obvious pain } \\
\text { Drowsiness } \\
\text { No consequences }\end{array}$ \\
\hline Player positions & $\begin{array}{l}\text { Goal keeper } \\
\text { Inside defender } \\
\text { Outside defender } \\
\text { Central midfielder } \\
\text { Right and left wing } \\
\text { Striker }\end{array}$ \\
\hline $\begin{array}{l}\text { Medical examinations by team } \\
\text { physician/other medical } \\
\text { personnel after the HII }\end{array}$ & $\begin{array}{l}\text { Treatment } \\
\text { No treatment } \\
\text { No view due to camera position }\end{array}$ \\
\hline Eligibility to continue playing & $\begin{array}{l}\text { No substitution } \\
\text { Substitution (immediate substitution } \\
\text { or delayed substitution) }\end{array}$ \\
\hline Head region of contact & $\begin{array}{l}\text { Face } \\
\text { Occipital, parietal, temporal, frontal } \\
\text { Hyperextension cervical spine } \\
\text { Unknown due to camera position }\end{array}$ \\
\hline $\begin{array}{l}\text { Severe impact on the head } \\
\text { Duel type }\end{array}$ & $\begin{array}{l}\text { yes } \\
\text { no } \\
\text { Header/aerial duel } \\
\text { Duel on the ground }\end{array}$ \\
\hline
\end{tabular}

tion). This magazine offers publicly available injury information. It provides data on diagnosis and time loss of each (head) injury. The magazine is published twice weekly with one journalist being responsible for one club and having contact with the press office of the clubs on a daily basis (in addition to players, coaches and staff members). Injury reports and summaries of each official league match are published. The online version also offers the opportunity for a free text search. Additionally, web pages (transfermarkt.de, ligainsider.de), social media of the players/teams (Twitter, Facebook, Instagram), team homepages and newsletters, TV sports channels, and local news were screened.

The subcategory 'suspected concussion' (independent from the original injury) was created [3]. This term included fractures of the zygomatic bone and skull as well as head contusions (to the skull and zygomatic bone only).

The severity classification of injuries was based on the time loss according to the consensus statement from previous football injury research [18]: slight (0 days), minimal (1-3), mild (4-7), moderate (8-28), and severe ( $>28)$.

\section{Match exposure}

Match exposure per team was calculated using the following calculation [18]: number of matches $x$ number of players on the field (11) $\times$ duration of the match in hours ( $1.5 \mathrm{~h}$ per match).

The analysis included all 34 matches being played by each club in the regular season. Cup games, friendly, and national games were not analysed.

\section{Inter-rater reliability}

Inter-rater reliability was checked by each rater reviewing 5 matches of his counterpart. Criteria for this re-evaluation was if the same $\mathrm{HII}$ including player identification and time during the match was identified by the other reviewer. In $79 \%$ of cases the incident was identified. $21 \%$ showed a disagreement between reviewers. Reasons for disagreements were difficult match situations with no clear view whether contact occurred.

\section{Statistics}

All statistical analyses were performed using Microsoft Excel 2019. $\mathrm{HII}$ and head injury incidence rates (IR) were calculated: incidence $=$ (number of injuries or Hlls / hours of match exposure) $\times 1000.95 \%$ confidence intervals (Cls) were calculated [19]:

Lower $95 \% \mathrm{Cl}=$ Incidence/e1.96 $\times$ (square root $[1 /$ number of incidents])

Upper $95 \% \mathrm{Cl}=$ Incidence $*$ e $1.96 \times($ square root $[1 /$ number of incidents])

For comparisons between head injuries and HIls, incidence rate ratios (IRR) were calculated. Descriptive data are presented as absolute numbers, percentages in parentheses, mean, and standard deviations (SD).

\section{Results}

\section{Match exposure and HIls}

306 matches were included with a match exposure of 10098 hours. The number of HIls was 1362 (IR 134.9/1000 match hours, $95 \% \mathrm{Cl}$ 127.9-142.2). Contact mechanisms of the HIls are shown in - Table 2. In 123 HIls (IR 12.2, $95 \%$ Cl 10.2-14.5), the contact was classified as severe.

\section{Head injuries}

Twenty-nine head injuries were diagnosed (IR of 2.9/1000 match hours, $95 \% \mathrm{Cl} 2.0-4.1$ ). Concussions/TBIs accounted for $48 \%$ (IR $1.4,0.8-2.3$ ), head/facial fractures $24 \%$ (IR $0.7,0.3-1.5$ ), head/facial contusions $21 \%$ (IR 0.6, 0.3-1.3), and lacerations/abrasions $7 \%$ (IR 0.2, 0.1-0.8). The 29 head injuries are included in the total number of HII, i.e. they were all detected during video analysis. The subgroup 'suspected concussion' accounted for $17 \%$ of all head injuries and included 4 head contusions and 1 fracture of the zygomatic bone. The IRR between $\mathrm{HII}$ and head injuries was $46.0(95 \% \mathrm{CI}$ 31.8-66.4). Of the $1362 \mathrm{HIls}, 2.1 \%$ were identified as head injuries.

The mean time loss was $8 \pm 10$ days (median 5 days, range 2-55 days). Nine head injuries were minimal, 10 mild, 9 moderate, and 1 severe. The highest time loss was observed in facial/head frac- 
Table 2 Observation of head impact incidents

\begin{tabular}{|c|c|c|}
\hline & n (\%) & $\begin{array}{l}\text { IR per } 1000 \text { match } \\
\text { hours }(95 \% \mathrm{Cl})\end{array}$ \\
\hline \multicolumn{3}{|l|}{ Contact mechanism } \\
\hline With opponent & $1156(85)$ & $114.5(108.1-121.3)$ \\
\hline With team mate & $57(5)$ & $5.6(4.4-7.5)$ \\
\hline Arm-to-head & 327 (24) & $32.4(29.1-36.1)$ \\
\hline Elbow-to-head & $265(20)$ & $26.2(23.3-29.6)$ \\
\hline Head-to-head & $171(13)$ & $16.9(14.6-19.7)$ \\
\hline Hand-to-head & $170(13)$ & $16.8(14.5-19.6)$ \\
\hline Shoulder-to-head & $109(8)$ & $11.0(9.0-13.0)$ \\
\hline Trunk-to-head & $47(4)$ & $4.7(3.5-6.2)$ \\
\hline Foot-to-head & $34(2.5)$ & $3.4(2.4-4.7)$ \\
\hline Pelvis/hip-to-head & $16(1)$ & $1.6(1.0-2.6)$ \\
\hline Knee-to-head & $16(1)$ & $1.6(1.0-2.6)$ \\
\hline Upper leg-to-head & $14(1)$ & $1.4(0.8-2.3)$ \\
\hline Lower leg-to-head & $6(<1)$ & $0.6(0.3-1.3)$ \\
\hline Trunk-to-trunk & $33(2.5)$ & $3.3(2.3-4.6)$ \\
\hline Shoulder-to-trunk & $15(1)$ & $1.5(0.9-2.5)$ \\
\hline Ball-to-head & $78(6)$ & $7.7(6.2-9.6)$ \\
\hline Ground-to-head & $59(4)$ & $5.8(4.5-7.5)$ \\
\hline Goalpost/object-to-head & 0 & 0 \\
\hline \multicolumn{3}{|l|}{ Head region of contact } \\
\hline Face & $616(45)$ & $61.0(56.4-66.0)$ \\
\hline Occipital & $312(23)$ & $30.9(27.7-34.5)$ \\
\hline Temporal & $174(13)$ & $17.2(14.9-20.0)$ \\
\hline Parietal & $130(10)$ & $12.9(10.8-15.3)$ \\
\hline Frontal & $59(4)$ & $5.8(4.5-7.5)$ \\
\hline Hyperextension cervical spine & $19(1)$ & $5.8(4.5-7.5)$ \\
\hline Unknown (camera position) & $59(4)$ & $1.9(1.2-3.0)$ \\
\hline \multicolumn{3}{|l|}{ Duel type } \\
\hline Header / aerial duel & $783(58)$ & $77.5(72.3-83.2)$ \\
\hline Duel on the ground & $447(33)$ & $44.3(40.4-48.6)$ \\
\hline \multicolumn{3}{|l|}{ Player behaviour after the HII } \\
\hline Player falls to the ground & $947(70)$ & $93.8(88.0-100.0)$ \\
\hline Player touches head & $931(68)$ & $92.2(86.5-98.3)$ \\
\hline Obvious pain & $498(37)$ & $49.3(45.2-53.8)$ \\
\hline Ataxia & $150(11)$ & $14.9(12.7-17.4)$ \\
\hline No consequences & $90(7)$ & $8.9(7.3-11.0)$ \\
\hline \multicolumn{3}{|l|}{$\begin{array}{l}\text { Medical examinations by team } \\
\text { physician/other medical } \\
\text { personnel }\end{array}$} \\
\hline Treatment & $1212(89)$ & $120.0(113.5-127.0)$ \\
\hline No treatment & $146(11)$ & $14.5(12.3-17.0)$ \\
\hline No view (camera position) & $4(<1)$ & $0.4(0.2-1.1)$ \\
\hline \multicolumn{3}{|l|}{ Eligibility to continue playing } \\
\hline No substitution & $1326(97)$ & $129.7(131.3-138.6)$ \\
\hline Substitution & $36(3)$ & $3.6(2.6-4.9)$ \\
\hline -Immediate substitution & 19 & $1.9(1.2-3.0)$ \\
\hline -Delayed substitution & 16 & $1.6(1.0-2.6)$ \\
\hline -Unclear timeframe & 1 & $0.1(0.0-0.7)$ \\
\hline \multicolumn{3}{|l|}{ Player position } \\
\hline Central midfielder & $378(28)$ & $36.5(33.0-40.5)$ \\
\hline Striker & $310(23)$ & $30.2(27.0-33.8)$ \\
\hline
\end{tabular}

$\checkmark$ Table 2 Continued.

\begin{tabular}{|c|c|c|}
\hline & n (\%) & $\begin{array}{l}\text { IR per } 1000 \text { match } \\
\text { hours }(95 \% \mathrm{Cl})\end{array}$ \\
\hline Inside defender & $254(19)$ & $25.1(22.2-28.3)$ \\
\hline Right and left midfielder & $222(16)$ & $21.7(19.0-24.8)$ \\
\hline Outside defender & $183(13)$ & $17.4(15.2-20.4)$ \\
\hline Goal keeper & $15(1)$ & $1.5(0.9-2.5)$ \\
\hline
\end{tabular}

tures (16 \pm 18 days, median 9 days, range $4-55$ ), followed by lacerations/abrasions ( $9 \pm 6$, median 9,4 and 13 ), concussions/TBls ( $6 \pm 5$, median 5 , range $2-20$ ), and head contusions ( $6 \pm 4$, median 4 , range $2-10$ ).

\section{Head injury mechanisms}

The most frequent head injury mechanism was head-to-head $(31 \%$, IR $0.9,95 \% \mathrm{Cl} 0.5-1.7)$, followed by elbow-to-head ( $21 \%$, IR 0.6 , $95 \% \mathrm{Cl} 0.3-1.3)$ and shoulders-to-head $(10 \%$, IR $0.3,95 \% \mathrm{Cl} 0.1$ $0.9)$. The comparison of the predominant $\mathrm{HII}$ and head injury mechanisms is shown in $\triangleright$ Fig. 2.

\section{Discussion}

The rationale of this study was to assess the research question of how frequently HIlls occur in professional football and how many of these are in fact identified as head injuries. Therefore, a third category of HIlls besides concussions (and more severe TBIs) and headers was characterized in order to shed light on the grey area between headers and head injuries. The most important finding of this study is the very high incidence rate $(\sim 135 / 1000 \mathrm{~h})$ of head impact incidents in professional football of which only a few were diagnosed as head injuries $(2.1 \%)$ according to the prospective injury registry. Secondarily, the underlying mechanisms were mainly arm and elbow-to-head and head-to-head contacts, which is similar to previous studies that described head injury mechanisms in football $[3,4]$. The actual number of head injuries and the corresponding head IR were low compared to previously published data in professional football with head-to-head and elbow-to-head being the most frequent head injury mechanism. This study aimed to initiate a debate whether HIls might be potentially relevant for the assessment of a "traumatic load" in players' brains because of their much higher frequency than concussions. Although this aspect was not within the scope of this study, it might become a relevant topic in near future.

\section{Head injury data and mechanisms}

Head injuries bear the risk of serious acute and long-term consequences [1,2]. Long-term sequelae of head injuries and repetitive head impacts include post-concussion syndrome (PCS) or - if they occur repetitively - chronic neurocognitive impairments (e.g. mild cognitive impairment $(\mathrm{MCl})$ ) or even chronic traumatic encephalopathy $(C T E)[1,2,20]$. Previous research has linked exposure to repetitive head impacts to potential long-term neurological sequelae [21-23]. Initially, head injury research predominantly focused on high-risk sports such as American football, rugby, boxing, or ice 


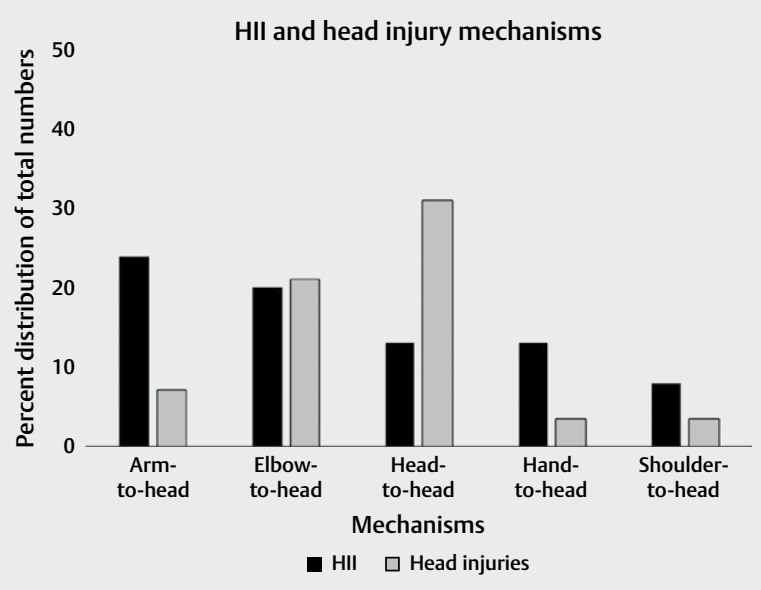

- Fig. 2 Five predominant head impact incident and head injury mechanisms.

hockey. However, head injury rates in football have also received some attention in recent years, despite the lower collision and contact rates in comparison to the aforementioned sports [1,2]. The IRs of head injuries in this study (2.88) were low compared to the high-risk sports [5, 24-26]. Compared to other football studies, however, the present IRs were slightly higher. Match IRs ranging from $0.70-2.22$ per 1000 match hours have been reported in recent years $[3,4,7,27-31]$. The main reason for the higher numbers in this database is probably the unique data collection approach, which is less dependent on the willingness of the medical staff to provide reports, which has potentially decreased under the growing media attention particularly for the concussion issue. The highest rates of head injuries were previously reported during FIFA World Cup tournaments (12.5 and 11.3) [32, 33]. It appears that it is rather difficult to compare head injury data from international tournaments with head injury data from regular league activity. The importance and the intensity of tournaments' matches are usually very high, which might suggest a more aggressive playing style resulting in an increase of all injuries including head injuries.

The head injuries in this study were most frequently caused by head-to-head (31\%) and elbow-to-head (21\%) contacts, which agrees with previous reports $[3,4]$. Head-to-head was previously considered to be the predominant injury mechanism with regard to the causation of head injuries [3, 4, 7, 34]. With a view toward head injury prevention, diminishing this injury mechanism is undoubtedly an important step in the near future. In 2006, the International Football Association Board changed the rules of the game and decided that direct and deliberate elbow-to-head blows have to be punished with a red card. This rule change has led to a reduction of these contacts by $23 \%$ as shown in a previous study [3]. A reduced number of elbow-to-head contacts was also described by another study after stricter interpretation of the rules [28]. Nevertheless, it appears to be impossible to completely prevent this injury mechanism because match dynamics, movement speed, applied techniques, equipment, and game play in general (e.g. tactics) seem to show a continuous evolution with increased physical and technical demands of the game [35-37].

\section{Head impact incidents and mechanisms}

The present analysis focused on a third category of HIls besides concussions (and more severe TBIs) and headers and revealed a high number of HIls during league matches. When match exposure is considered, the IR reaches $\sim 135$ per 1000 match hours. Such HIls may be considered "sub-concussive" blows; this term describes a cranial impact with potential neuronal changes similar to those in concussion but without the symptoms of a concussion [22]. HIIs have been less in focus than head injuries and headers, especially in terms of long-term sequelae [38], although this third category might be relevant for an assessment of the "traumatic load" in players' brains. Two previously published video observation reports of head collision events during the FIFA World Cup 2014 and 2018 detected an IR of approximately 33 and 53 , respectively $[14,15]$. In over $60 \%$ of the incidents, the players did not receive an assessment for concussion following an established protocol, although they showed signs of a head injury according to the authors' standardized assessment. It is likely that the real number of head injuries is higher than previously reported as some injuries might remain unreported, particularly concussions [8-10]. Their signs and symptoms can rapidly change as well as disappear [20]. This injury category is considered to be one of the most complex acute ones to diagnose, assess, and manage [20]. For the present analysis, it appears impossible to determine how many HIls were in fact undiagnosed head injuries. At least $9 \%$ of all HIls were classified as severe, of which $43 \%$ received medical treatment, but only $7 \%$ were diagnosed as head injuries according to the media-based information. Although rather speculative, if only these severe HIls had been undiagnosed as head injuries, it would make this injury location one of the most frequently affected body parts compared to other injury locations [6, 39, 40].

Head contact with the opponent or team mate was apparent in $85 \%$ of all HIls. As all HIls are generally contact-related, there was a biomechanical force transmitted directly to the head, which is part of the general concussion definition $[1,41]$. The most frequent mechanism was the arm and elbow (combined), followed by headto-head and hand-to-head contacts. A header duel was apparent in most of all HIls. These trends are compatible with studies determining the head and elbow as well as header duels as the most frequent head injury mechanisms and causes [3, 4, 7, 34]. In most HIls the player showed signs of at least a minor head injury when considering the large number of players that required a medical examination by the team physician or other medical personnel or touched their head after the incident in obvious pain. As a matter of fact, in $97 \%$ of the HIls, affected players were not substituted, giving rise to the assumption of some unrecognised head injuries. Of the HIls classified as severe, merely $16 \%$ were substituted. Additionally, contact locations on the players' heads are potentially important for head injuries. Temporal, occipital, or parietal contact on the head are likely signs for an unexpected contact with the opponent, etc., and such scenarios likely limit the preparedness of players for the incoming impact with the consequence of more damage [17].

The present analysis may strengthen further in-depth discussions within the medical and scientific community about the management of this newly defined category of HIls and, accordingly, head injuries. Equally important as reducing the number of head 
injuries is improving the accuracy in diagnosing and managing TBls. Although injury-preventing rules have been introduced (for instance, a red card for elbow-to-head contacts and FIFA's concussion rule with a 3-minute break), there are still debates around the implementation of a more extensive 'concussion safety protocol'.

\section{Methodological considerations}

Ideally, the video recordings should provide various perspectives, slow motion, and display high-resolution quality, which was not available for all scenes. Throughout the analysis, difficult HIls were discussed and a final assessment made. Matches other than regular league matches and training sessions were not included and this can be regarded as a limitation of this study. Relying solely on video reviews of all matches without having access to actual injury reports is arguable, but access to injury reports of the teams is somewhat impossible. Teams do not intend to share sensitive data with the media. However, the underlying methodological standards (media-based injury registries) have previously been used in injury research [3, 4, 42-44]. The advantage is the massive increase in availability of media-based information $[6,7,28,45,46]$. Especially, head injuries have received increased attention in football in recent years. In particular, concussions were subject of public discussions described by media sources. The present media-based data were not validated with medical records by each team's medical departments, which are typically considered the gold standard $[6,28,32,33,47]$. But even for reports from the medical staff there is no guarantee of data integrity as a recently published study found that medical staff reports underestimated the incidence of timeloss injuries by up to $20 \%$ [46].

The level of investigation and depth of media coverage allows for adequate data collection and therefore, the present analysis is considered to be fairly complete. Nevertheless, these injury data were extracted from non-medical publications and their accuracy should be interpreted with some caution.

This analysis attempted to shed some light on the discussion of unreported head impacts, but it cannot precisely quantify how many of the HIls may in fact be undiagnosed head injuries. Wearable sensor systems or high-resolution video (e.g. calculating peak linear accelerations) can help to identify the severity of HIls and the impacts on the brain in future [48]. However, regarding the biomechanical forces to the head due to contacts with the opponents or team mates (in some rare cases the ball), it can be assumed that a considerable number of them has been a head injury.

We used the diagnosis 'suspected concussion' in the case of certain traumas as substantial force is required to cause a facial fracture, and this can well be associated with an intracranial injury $[49,50]$. Facial fractures were included only if they affected the zygomatic bone or the skull. Additionally, head contusions to the aforementioned bones counted towards this category. Injuries affecting the nasal bone such as fractures or contusions, mandibular fractures, and lacerations/abrasions were excluded from that category as such injuries may not necessarily transmit the force of impact directly to the cranium and the brain, respectively.

\section{Conclusions}

The number of HIls is high when including a third category besides headers and head injuries. The present results add valuable information as head injuries and other head impacts may be potential causes of cumulative brain damage and/or neurodegeneration. The identification of HIls and additionally head injury severity should be improved during on-field assessment as many (potential) head injuries might go unrecognized based on the large number of HIls. For clinical practice, head impacts bear the risk of short- and longterm health sequelae, the awareness of a considerable number of incidents apart from concussions and headers is important as the identification of head injury and head impact mechanisms is essential to develop preventative measures in the future.

\section{Acknowledgements}

The authors wish to thank the "kicker Sportmagazin" magazine for granting access to their online issues. Access to the video recordings were obtained from the Deutsche Fußball Liga (DFL; German Football League organisation).

\section{Conflict of Interest}

The authors declare that they have no conflict of interest.

\section{References}

[1] Harmon KG, Clugston JR, Dec K et al. American Medical Society for Sports Medicine position statement on concussion in sport. $\mathrm{Br}$ J Sports Med 2019; 53: 213-225. doi:10.1136/bjsports-2018-100338

[2] Levy ML, Kasasbeh AS, Baird LC et al. Concussions in soccer: A current understanding. World Neurosurg 2012; 78: 535-544. doi:10.1016/j. wneu.2011.10.032

[3] Beaudouin F, Aus der Funten K, Tross T et al. Head injuries in professional male football (soccer) over 13 years: $29 \%$ lower incidence rates after a rule change (red card). $\mathrm{Br}$ J Sports Med 2019; 53 : 948-952. doi:10.1136/bjsports-2016-097217

[4] Beaudouin F, der Funten KA, Tross T et al. Time trends of head injuries over multiple seasons in professional male football (soccer). Sports Med Int Open 2019; 3: E6-E11. doi:10.1055/a-0808-2551

[5] Zuckerman SL, Kerr ZY, Yengo-Kahn A et al. Epidemiology of sports-related concussion in NCAA athletes From 2009-2010 to 2013-2014: incidence, recurrence, and mechanisms. Am J Sports Med 2015; 43: 2654-2662. doi:10.1177/0363546515599634

[6] Ekstrand J, Hagglund M, Walden M. Injury incidence and injury patterns in professional football: The UEFA injury study. $\mathrm{Br}$ J Sports Med 2011; 45: 553-558. doi:10.1136/bjsm.2009.060582

[7] Nilsson M, Hagglund M, Ekstrand ] et al. Head and neck injuries in professional soccer. Clin J Sport Med 2013; 23: 255-260. doi:10.1097| JSM.0b013e31827ee6f8

[8] Meehan WP 3rd, Mannix RC, O'Brien MJ et al. The prevalence of undiagnosed concussions in athletes. Clin J Sport Med 2013; 23 : 339-342. doi:10.1097/JSM.0b013e318291d3b3

[9] Williamson I], Goodman D. Converging evidence for the under-reporting of concussions in youth ice hockey. Br J Sports Med 2006; 40: 128-132. Discussion 128-132. doi:10.1136/bjsm.2005.021832 
[10] Meier TB, Brummel B], Singh R et al. The underreporting of self-reported symptoms following sports-related concussion. J Sci Med Sport 2015; 18: 507-511. doi:10.1016/j.jsams.2014.07.008

[11] Broglio SP, Vagnozzi R, Sabin M et al. Concussion occurrence and knowledge in italian football (soccer). J Sports Sci Med 2010; 9: 418-430

[12] Feddermann-Demont N, Straumann D, Dvorak J. Return to play management after concussion in football: Recommendations for team physicians. J Sports Sci 2014; 32: 1217-1228. doi:10.1080/02640414. 2014.918273

[13] Putukian M, Aubry M, McCrory P. Return to play after sports concussion in elite and non-elite athletes? $\mathrm{Br}$ J Sports Med 2009; 43: Suppl 1 i28-31. doi:10.1136/bjsm.2009.058230

[14] Cusimano MD, Casey J, Jing R et al. Assessment of head collision events during the 2014 FIFA World Cup Tournament. JAMA 2017; 317 : 2548-2549. doi:10.1001/jama.2017.6204

[15] Premkumar A, Farley KX, Anastasio AT et al. Video assessment of the frequency and evaluations of head collision events during the 2018 World Cup Tournament. JAMA Neurol 2019; 76: 232-234. doi:10.1001/jamaneurol.2018.3462

[16] Harriss DJ, MacSween A, Atkinson G. Ethical standards in sport and exercise science research: 2020 update. Int J Sports Med 2019; 40: 813-817. doi:10.1055/a-1015-3123

[17] Beaudouin F, Aus der Funten K, Tross T et al. Match situations leading to head injuries in professional male football (soccer)-a video-based analysis over 12 years. Clin J Sport Med. 2018. doi:10.1097| JSM.0000000000000572

[18] Fuller CW, Ekstrand J, Junge A et al. Consensus statement on injury definitions and data collection procedures in studies of football (soccer) injuries. Br J Sports Med 2006; 40: 193-201. doi:10.1136/ bjsm.2005.025270

[19] Hagglund M, Walden M, Ekstrand J. Previous injury as a risk factor for injury in elite football: A prospective study over two consecutive seasons. Br J Sports Med 2006; 40: 767-772. doi:10.1136/bjsm.2006.026609

[20] McCrory P, Meeuwisse W, Dvorak J et al. Consensus statement on concussion in sport-the 5 (th) international conference on concussion in sport held in Berlin, October 2016. Br ] Sports Med 2017; 51: 838-847. doi:10.1136/bjsports-2017-097699

[21] Hunter LE, Branch CA, Lipton ML. The neurobiological effects of repetitive head impacts in collision sports. Neurobiol Dis 2019; 123: 122-126. doi:10.1016/j.nbd.2018.06.016

[22] Bailes JE, Petraglia AL, Omalu BI et al. Role of subconcussion in repetitive mild traumatic brain injury. J Neurosurg 2013; 119 : 1235-1245. doi:10.3171/2013.7.JNS121822

[23] Caccese JB, Best C, Lamond LC et al. Effects of repetitive head impacts on a concussion assessment battery. Med Sci Sports Exerc 2019; 51: 1355-1361. doi:10.1249/MSS.0000000000001905

[24] Casson IR, Viano DC, Powell JW et al. Twelve years of national football league concussion data. Sports Health 2010; 2: 471-483. doi: $10.1177 / 1941738110383963$

[25] Cross M, Kemp S, Smith A et al. Professional Rugby Union players have a $60 \%$ greater risk of time loss injury after concussion: A 2-season prospective study of clinical outcomes. Br J Sports Med 2016; 50: 926-931. doi:10.1136/bjsports-2015-094982

[26] Gissane $C$, Jennings $D$, Kerr $K$ et al. Injury rates in rugby league football: Impact of change in playing season. Am J Sports Med 2003; 31: 954-958. doi:10.1177/03635465030310063501

[27] Andersen TE, Arnason A, Engebretsen L et al. Mechanisms of head injuries in elite football. Br J Sports Med 2004; 38: 690-696. doi:10.1136/bjsm.2003.009357

[28] Bjorneboe J, Bahr R, Dvorak J et al. Lower incidence of arm-to-head contact incidents with stricter interpretation of the Laws of the Game in Norwegian male professional football. Br J Sports Med 2013; 47: 508-514. doi:10.1136/bjsports-2012-091522
[29] Kristenson K, Bjorneboe J, Walden M et al. The nordic football injury audit: Higher injury rates for professional football clubs with third-generation artificial turf at their home venue. Br J Sports Med 2013; 47: 775-781. doi:10.1136/bjsports-2013-092266

[30] Carling C, Orhant E, LeGall F. Match injuries in professional soccer: Inter-seasonal variation and effects of competition type, match congestion and positional role. Int J Sports Med 2010; 31: 271-276. doi:10.1055/s-0029-1243646

[31] Stubbe JH, van Beijsterveldt AM, van der Knaap S et al. Injuries in professional male soccer players in the Netherlands: A prospective cohort study. J Athl Train 2015; 50: 211-216. doi:10.4085/1062-605049.3.64

[32] Fuller CW, Junge A, Dvorak J. A six year prospective study of the incidence and causes of head and neck injuries in international football. Br J Sports Med 2005; 39 Suppl 1: i3-9. doi:10.1136/ bjsm.2005.018937

[33] Junge A, Dvorak J. Injury surveillance in the World Football Tournaments 1998-2012. Br J Sports Med 2013; 47: 782-788. doi:10.1136/ bjsports-2013-092205

[34] Fuller CW, Smith GL, Junge A et al. The influence of tackle parameters on the propensity for injury in international football. Am J Sports Med 2004; 32: 43S-53S. doi:10.1177/0363546503261248

[35] Barnes C, Archer DT, Hogg B et al. The evolution of physical and technical performance parameters in the English Premier League. Int J Sports Med 2014; 35: 1095-1100. doi:10.1055/s-0034-1375695

[36] Bush M, Barnes C, Archer DT et al. Evolution of match performance parameters for various playing positions in the English Premier League. Hum Mov Sci 2015; 39: 1-11. doi:10.1016/j.humov.2014.10.003

[37] Wallace JL, Norton KI. Evolution of World Cup soccer final games 1966-2010: Game structure, speed and play patterns. J Sci Med Sport 2014; 17: 223-228. doi:10.1016/j.jsams.2013.03.016

[38] Putukian M, Echemendia R], Chiampas G et al. Head injury in soccer: from science to the field; summary of the head injury summit held in April 2017 in New York City, New York. Br J Sports Med. 2019. doi:10.1136/bjsports-2018-100232

[39] Hagglund M, Walden M, Ekstrand J. Injury recurrence is lower at the highest professional football level than at national and amateur levels: does sports medicine and sports physiotherapy deliver? . Br J Sports Med 2016; 50: 751-758. doi:10.1136/bjsports-2015-095951

[40] Lopez-Valenciano A, Ruiz-Perez I, Garcia-Gomez A et al. Epidemiology of injuries in professional football: A systematic review and metaanalysis. Br J Sports Med. 2019. doi:10.1136/bjsports-2018-099577

[41] McCrory P, Meeuwisse WH, Kutcher JS et al. What is the evidence for chronic concussion-related changes in retired athletes: behavioural, pathological and clinical outcomes? . Br J Sports Med 2013; 47: 327-330. doi:10.1136/bjsports-2013-092248

[42] Krutsch V, Grechenig S, Loose O et al. Injury analysis in professional soccer by means of media reports - only severe injury types show high validity. Open Access J Sports Med 2020; 11: 123-131. doi:10.2147| OAJSM.S251081

[43] Krutsch W, Memmel C, Krutsch V et al. High return to competition rate following ACL injury - A 10-year media-based epidemiological injury study in men's professional football. Eur J Sport Sci 2020; 20: 682-690. doi:10.1080/17461391.2019.1648557

[44] Leventer L, Eek F, Hofstetter S et al. Injury patterns among elite football players: a media-based analysis over 6 seasons with emphasis on playing position. Int J Sports Med 2016; 37: 898-908. doi:10.1055/s-0042-108201

[45] Walden M, Hagglund M, Ekstrand J. UEFA Champions League study: A prospective study of injuries in professional football during the 2001-2002 season. Br J Sports Med 2005; 39: 542-546. doi:10.1136/ bjsm.2004.014571 
[46] Bjorneboe J, Florenes TW, Bahr R et al. Injury surveillance in male professional football; is medical staff reporting complete and accurate? Scand J Med Sci Sports 2011; 21: 713-720. doi:10.1111/j.1600-0838.2009.01085.x

[47] Junge A, Dvorak J. Football injuries during the 2014 FIFA World Cup. $\mathrm{Br}$ J Sports Med 2015; 49: 599-602. doi:10.1136/bjsports-2014-094469

[48] O'Connor KL, Rowson S, Duma SM et al. Head-impact-measurement devices: A systematic review. J Athl Train 2017; 52: 206-227. doi:10.4085/1062-6050.52.2.05
[49] Pappachan B, Alexander M. Correlating facial fractures and cranial injuries. J Oral Maxillofac Surg 2006; 64: 1023-1029. doi:10.1016/j. joms.2006.03.021

[50] Keenan HT, Brundage SI, Thompson DC et al. Does the face protect the brain? A case-control study of traumatic brain injury and facial fractures. Arch Surg 1999; 134: 14-17. doi:10.1001/archsurg.134.1.14 